\title{
Los ángeles de Charly: entre el ser nacional ideal del Proceso de Reorganización Nacional y el ser real del rock nacional argentino
}

\author{
Mara Favoretto (University of Melbourne, Melbourne, Australia) \\ mara.f@unimelb.edu.au
}

Timothy Wilson (University of Alaska, Fairbanks, U.S.A.)

tdwilson2@alaska.edu

\begin{abstract}
Resumen: Desde su inicio, la dictadura argentina que se auto-denominó el Proceso de Reorganización Nacional se propuso la consolidación de un único ser nacional, una identidad nacional compartida por todos los argentinos, que se basaba en una exagerada e idealizada visión de la tradición hispánica de la figura heterosexual masculina fuerte y la figura femenina sumisa y obediente. En sus declaraciones y comunicados oficiales, el Proceso intentaba la reinstauración de valores correspondientes a un pasado imaginado, que constituía casi una caricatura de ideales clásicos como el "ángel del hogar" y el "código de honor". Pero esta represiva maquinaria censora y propagandista vio su contrapunto en otra "máquina": nace en los mismos días que el Proceso una banda de rock del músico Charly García llamada La Máquina de Hacer Pájaros. El discurso poético de La Máquina contradecía sutilmente el discurso del régimen, en momentos en que era sumamente peligroso disentir. En este trabajo se analiza el discurso del ser nacional ideal, que el régimen militar intentaba imponer por la fuerza, en contraste con el ser nacional real que contraponían las letras de las canciones de Charly García. En contra del rol tradicional de esposas e hijas obedientes que se bombardeaba desde el discurso oficial, en las canciones de La Máquina de Hacer Pájaros, las mujeres eran protagonistas: heroínas, diosas, y bailarinas. En lugar del "ángel del hogar" que proponía el Proceso, los "ángeles" en las canciones de García son las mujeres independientes del siglo XX.
\end{abstract}

Palabras clave: rock y dictadura; rock en Argentina; Charly García y La Máquina.

Charly's Angels: between the idealized ser nacional of the Argentine Proceso and the demythologized ser nacional of Argentine Rock

Abstract: From its very beginning, the Argentine Proceso dictatorship ("Proceso de Reorganización Nacional") of 1976-1983 proposed a single "Argentine Way of Life" ("ser nacional argentino"), a national identity to be shared by all Argentines, which was based on an exaggerated ideal of the Hispanic tradition: a strong heterosexual masculine figure and a submissive and obedient female figure. In its declarations and official communiqués, the Proceso regime attempted to recreate an imaginary past, which amounted to a caricature of classic ideals such as the "Angel of the home" ("Angel del hogar"), and the "Latin Honor Code". But this repressive machinery of censorship and propaganda was countered by another "machine," a rock band headed by Charly García called La Máquina de Hacer Pájaros. The poetic discourse of the La Máquina subtly contradicted that of the regime, at a time in which any dissent was extremely dangerous. In this study, we shall analyze the monolithic and idealized discourse of the ser nacional, which the regime imposed, in contrast to the more realistic and polyphonic vision of national identity as seen in the lyrics of Charly Garcia's songs. Whereas the regime bombarded Argentines with rhetoric about obedient wives and daughters, in La Máquina songs, women are protagonists: heroines, goddesses, and dancers. Garcia replaces the nineteenth-century "Angel of the home" proposed by the regime with his own angels: the independent women of the twentieth century.

Keywords: rock and dictatorship; rock in Argentina; Charly García and La Máquina. 
"Making music isn't a way of expressing ideas; it is a way of living them" (FRITH, 1996, p.111)

"...hay algo que nadie puede explicar: por qué la niña ríe en vez de Ilorar"
(GARCIA, Sui Generis, "Fabricante de mentiras", Adiós Sui Generis II, 1975)

\section{Introducción}

La masividad de la audiencia del músico de rock argentino Charly García lo ha colocado en un estadio canónico de la cultura popular de este país, ya no sólo como representante principal de este género musical, sino como figura emblemática que surgió antes de la dictadura militar 1976-83, logró fama durante la misma y se estableció como ícono indiscutible, reconocido mundialmente como uno de los músicos de rock nacional argentino más destacados (FAVORETTO, 2010, p.207). ${ }^{1}$ Más allá de sus condiciones musicales, García se ha destacado por su habilidad para evadir el aparato censor del Proceso a través de la poética cifrada de las letras de sus canciones ${ }^{2}$ y en las décadas posteriores a la dictadura se ha convertido en un mito (SANCHEZ, 2007, p.45).

Aunque no se notó desde un principio, y los mensajes codificados en las letras metafóricas de García pasaran desapercibidas por un tiempo, cada uno de sus álbumes producidos durante la dictadura supo ofrecer un punto de vista crítico respecto a la realidad y, a partir de varias de sus canciones, mediante la ironización del status quo, se generó, dentro del rock, un foco de resistencia al Proceso (FAVORETTO, 2010, p.211). Sin embargo, los dos álbumes compuestos en 1976 y 1977, período que coincide con la etapa más violenta del Proceso, aún no han recibido una atención detallada. En una de sus muchas conversaciones con Sergio Marchi, Garcia le explicaba:

\footnotetext{
Yo creo en la frontera: es la imaginación de uno, la propia inteligencia para plantear una respuesta de un modo que pueda ser entendida por gente que a uno le interesa y no entendida por gente que a uno no le interesa y que pueden llegar al punto de matarte. (MARCHI, 2007, p.35-36)
}

No se trataba de una exageración: la violencia del Proceso no es en absoluto desconocida. Hubo 30.000 personas desaparecidas de las cuales 27.000 eran civiles (WILSON, 2010, p.27). Tal violencia no se trataba de "una guerra y sus consecuentes víctimas", como quería justificarse desde las esferas militares, sino de un plan cuidadosamente organizado y un proyecto ideológico a largo plazo, que controlaría todos los aspectos de la vida pública a través de un control social excesivo, una reforma educativa y la censura de los medios. ${ }^{3}$ Varios críticos internacionales han analizado diversos aspectos del Proceso intentando una aproximación a las motivaciones detrás del accionar represivo y violento del régimen. Por ejemplo, KLEIN (2007, p.120) insiste en razones económicas y argumenta el apoyo estadounidense para la consolidación de políticas de libre comercio. FEITLOWITZ (1998, p.153), que realizó un estudio minucioso de la retórica del régimen, asegura que el objetivo del Proceso era controlar las palabras para así poder controlar las mentes. Agrega que el operar de la censura apuntaba a eliminar el colectivismo, no sólo de la cultura, sino del pensamiento mismo. Para TAYLOR (1997, p.95), el control comenzaba por lo cotidiano para llegar así a controlar toda la nación, en la que los ciudadanos ideales serian aquellos que conscientemente controlaran cada una de sus palabras. Como explica WILSON (2010, p.18), el control de los medios de comunicación y de la expresión pública aseguraría a las autoridades militares el control de la cultura argentina y del rumbo que tomaría el país.

Si bien las motivaciones pueden haber sido varias, el análisis del discurso del régimen deja claro que lo que el Proceso se proponía, entre otras cuestiones, era la consolidación de un único ser nacional, compartido por todos los argentinos, una identidad nacional basada en tradiciones hispánicas y en valores occidentales y cristianos. Esta visión del ser nacional ideal era patriarcal, con una figura heterosexual masculina fuerte y una figura heterosexual femenina sumisa y obediente. La imagen del "ángel del hogar", que se ubicaba en el núcleo de las construcciones de la feminidad en España y Latinoamérica durante el siglo XIX y que relegaba a la mujer al ámbito hogareño exclusivamente, parecía aún tener vigencia en el discurso del régimen. Por lo tanto, los músicos de la época se encontraron frente a un desafío: librar una batalla simbólica contra las ideas pacatas que no los representaban y, a su vez, desafiar la maquinaria censora que les impedía expresarse.

En este trabajo nos proponemos analizar primero el discurso del ser nacional ideal que proponía el régimen militar y que intentaba imponer por la fuerza, con especial atención a su visión del rol de la mujer en la sociedad argentina. Luego, se analiza el ser nacional real que se contraponía al oficial a través de las letras de las canciones de Charly García en la década del 70. En contra del rol tradicional de madres y esposas obedientes que se bombardeaba desde el discurso oficial, en las canciones de García en los años del Proceso las mujeres eran heroínas, diosas, bailarinas y protagonistas. Los verdaderos "ángeles" en las canciones de García no eran el "ángel del hogar" del modelo hispánico del siglo XIX sino las mujeres independientes del siglo XX. Este aspecto particular de la producción de García aún no ha sido exhaustivamente explorado y lo consideramos fundamental para un acercamiento a una más completa interpretación de la obra de este músico. 


\section{Entre ángeles y demonios}

Charly García pareciera tener una relación cronológica especial con el Proceso. Su banda Sui Generis, en la época pre-dictadura, ya era una especie de termómetro que mostraba la temperatura que se vivía en el ambiente caótico que desencadenó el golpe de 1976. ALABARCES (1995, p.68) afirma que esta banda "pone en evidencia el imaginario de los nuevos sectores juveniles (en el sentido etario) de los 70". Las canciones de Sui Generis, sin duda, asumen el conflicto que estalla en la Argentina, identifican contradicciones y buscan espacios que permitan la identificación imaginaria de los actores a los que la violencia política margina de las prácticas militantes (p.68). Luego de la censura a su álbum Instituciones y la prohibición para menores de 18 años de la película Adiós, Sui Generis (KAMIN, 1976), que se grabó en vivo en el concierto despedida de la banda, "Sui institucionaliza el rock como fenómeno de masas" (ALABARCES, 1995, p.70). El recital masivo aparece en 1976 -coincidiendo con el inicio de la dictadura- como la forma más adecuada de reemplazar la agrupación colectiva y pública. ${ }^{4} \mathrm{~A}$ partir de entonces García se constituyó, de diversas maneras, en un contra-cronista de la dictadura, cuyo medio de expresión en una sociedad represiva era su música. A través de sus canciones, re-interpretaba los eventos políticos y la retórica de los generales, inicialmente para sus seguidores y, eventualmente, cuando el rock nacional alcanzó mayor popularidad, para la nación toda.

En este contexto, las letras de las canciones compuestas por García en los 70 parecían contestar ideológicamente al Proceso y ofrecer alternativas. Uno de los mejores ejemplos lo constituye el nombre de su banda, La Máquina de Hacer Pájaros. Apenas iniciado el Proceso, en marzo de 1976, García anunció la formación de su nueva banda, de nombre sugerente, que debutó en mayo del mismo año. Ambos grupos -el trío militar y el quinteto de rock- compartieron algo más que la fecha de nacimiento. En cierta forma representan las caras opuestas de una misma moneda. La Máquina, una banda de rock sinfónico, y El Proceso, un plan de gobierno, presentaban formas opuestas de mirar el mundo y la realidad de los jóvenes argentinos. Ambas polaridades parecieran haberse desarrollado por oposición dialéctica la una de la otra: la junta deseaba eliminar a la juventud "subversiva" y manejaba su discurso acorde a este objetivo. Por otro lado, la identidad alternativa y contestataria que García ya venía conformando desde sus inicios con Sui Generis y su experiencia directa con la censura se solidificó bajo la dictadura. Esta identidad alternativa en las canciones del rock de García incorporaban los valores de los jóvenes de su generación, que distaban de los que se les quería imponer desde el poder.

Estas dos visiones contradictorias se presentaban como sistemas de valores enfrentados que permeaban sus discursos: una "máquina" enfrentaba a otra, llamada "Proceso". En síntesis, Charly García utilizaba el rock como plataforma para contradecir la ideología oficial. Los ejes temáticos y el estilo de La Máquina funcionaban como negativos fotográficos de los comunicados oficiales del régimen. Mientras que el Proceso de Reorganización Nacional proyectaba un idilico ser nacional unilateral basado en ideales tradicionales hispánicos, concepciones conservadoras patriarcales y católicas, y un rol femenino tradicional, García representaba a las mujeres como seres poderosos y libres, utilizaba elementos de la cultura popular local e insertaba pequeños cortes de películas de la era dorada del cine argentino para compensar lo que faltaba incluir en el mito glorioso del ser nacional. Sin ser un pastiche, las canciones de Garcia son un discurso coherente y polifónico contrapuesto a la visión autoritaria y paternalista como única posible, presentada por el régimen. Este discurso alternativo destruía sutilmente el mito de la pasividad de la mujer y el poder del hombre, y dejaba en evidencia que el ser nacional argentino no era sólo uno.

\section{Los ideales del ser nacional}

Para el régimen, la homogeneidad de los miembros de la gran familia del estado debía ser lograda a través de la unificación ideológica de la identidad y esencia argentinas. El mito del ser nacional estaba basado en lo que los militares consideraban "tradición" y era un componente fundamental de su discurso político. Como ejemplo de patriotismo retórico, podemos citar al Teniente Coronel Hugo Pascarelli, quien en marzo de 1977 decía: "La lucha que liberamos no conoce límites morales. Se realiza más allá del bien y del mal." (CLARIN, Suplemento especial, 15). Estar más allá del bien y del mal suponía una función mesiánica en un marco conceptual sublime, hasta épico. Las leyes morales que sustentaban el ideal del ser nacional parecian ser abstractas y cósmicas, ya que denotaban un orden a gran escala, que, según Pascarelli, eran ilimitadas.

Desde los discursos oficiales, el presidente de la Junta Militar convocaba a los ciudadanos a unirse en la esencia única nacional. Por ejemplo, con motivo de cumplirse un año del golpe de estado, a fines de marzo de 1977, el Presidente Videla dirige un discurso a la población en el que formula una propuesta de unión nacional. En dicho discurso, Videla valora el apoyo de la ciudadanía a las Fuerzas Armadas, que "ha acompañado a sus soldados a la victoria que hoy se vislumbra y que pertenece a la nación toda." Agrega que es meta constante del gobierno la de "instaurar un orden político auténtico y duradero, basado en los valores de la libertad, la igualdad, la justicia y la seguridad" (BLAUSTEIN \& ZUBIETA, 2006, p.179). EI valor de igualdad al que seguramente se refería Videla, era más bien un rechazo de la diversidad. El orden "auténtico" que vislumbraba, entonces, implica que era el único, para él, verdadero. De aquí se entiende que su propuesta de unión nacional era, en realidad, más que una propuesta, un ultimatum: el que no aceptara este ser nacional sería considerado subversivo y, por lo tanto, un enemigo peligroso (FAVORETTO, 2010, p.61). 
Los militares del Proceso hablaban de la "recuperación" del ser nacional, es decir, de reavivar los mitos de la identidad nacional argentina con el fin de redefinir el modo en que los argentinos se veían a sí mismos y aquello con lo que se identificaban. Todo lo que el Proceso considerara un obstáculo para la definición de un ser nacional basado en valores tradicionales hispánicos sobre Dios, la Patria, la familia y el honor, sería eliminado. El vocablo "recuperación" indicaba que se trataba de un ideal del pasado que se había perdido y que consideraban necesario reinstaurar en el imaginario social. Las temáticas de los comunicados oficiales incluían el rechazo al relativismo en favor de una identidad nacional auténtica y a la conducta de los ciudadanos, que debían seguir determinados modelos de género. De tal manera que muchos mensajes eran dirigidos al género femenino:

\section{Convocamos a las mujeres a ser madres de la República, que le enseñen a caminar, que le enseñen a pensar, que le enseñen a sonreír. Nunca la Argentina necesitó tanto de las mujeres como en estos momentos (MASSERA, 1979, p.54-55).}

Otros mensajes les cuestionaban cómo habian educado a sus hijos, o si sabían dónde estaban sus hijos en aquel momento. Parecía que la responsabilidad de los hijos era una cuestión principalmente a cargo de la mujer. Ellas debian cumplir con su parte asignada a fin de frenar la amenaza subversiva a la nación (FEITLOWITZ, 1998, p.37-38). Además de los dictámenes sobre el rol de los ciudadanos, el Proceso se apoyaba en un aparato censor que funcionaba de una manera clandestina. Los estudios de INVERNIZZI \& GOCIOL (2002), INVERNIZZI (2005), AVELLANEDA (1986, 1985), FOSTER (1995), WILSON (2008) y FAVORETTO (2010) ya han expuesto el funcionamiento de una maquinaria censora que operaba a través de listas negras, prohibiciones y una represión violenta, siendo la música uno de sus blancos más afectados. Sin embargo, como se demostrará en breve, hubo artistas como García que lograron burlar la maquinaria censora-represora a través del contenido temático de sus composiciones musicales.

\section{El ángel del hogar y el ser nacional real}

La estrategia de la retórica oficial de comparar al país con una gran familia era, aunque en apariencia simple, no menos sofisticada. Los ciudadanos, como miembros de esa familia, eran llamados a colaborar con el proceso para "depurar" a sus hermanos que se habían equivocado en sus decisiones. El gobierno era identificado como el padre de familia que, en una sociedad conservadora, es el que da órdenes y toma decisiones. Esta comparación permitía a los militares justificar la represión en algunas ocasiones. Como "jefe de la familia" su deber era mantener el control, premiando o castigando a los miembros del núcleo familiar por sus acciones cuando fuese necesario. Algunos representantes del clero apoyaban esta idea paternalista, como por ejemplo Monseñor Adolfo Tortolo, quien en declaraciones a la revista Para Ti el 28 de junio de 1976, decía: la gran familia argentina, nuestra Nación, está herida y sangrando.. Más de una familia está hundida en la amargura por alguien que se fue, por alguien que no supo vencer una pasión o por alguien que abandonó el hogar por la seducción de una aventura criminal, a veces. (BLAUSTEIN \& ZUBIETA, 2006, p.132)

Tanto el General Videla como el Almirante Massera se ajustaban a la imagen de ese padre bueno, fuerte y firme, que velaba por el bien de su familia. El otro vínculo institucional fuerte lo estableció con la Iglesia Católica. Estas dos entidades, "Dios y la Patria," estarán permanentemente presentes en sus discursos. En su pueblo natal, Mercedes, durante el acto central de la inauguración del Mercado de Hacienda, en 1980, Videla pronunció estas palabras:

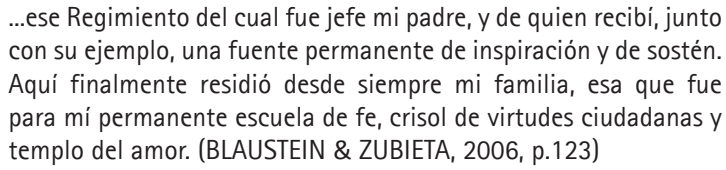
con su ejemplo, una fuente permanente de inspiración y de sostén. Aquí finalmente residió desde siempre mi familia, esa que fue para mi permanente escuela de fe, crisol de virtudes ciudadanas y templo del amor. (BLAUSTEIN \& ZUBIETA, 2006, p.123)

La consigna que, según Videla, guiaba su accionar era "Dios, Patria y Hogar." Se había casado a los 23 años con su única novia. Una descripción de un allegado a su vida personal lo define como "muy católico y abnegado con la familia. Para él la vida eran la familia y el ejército" (BLAUSTEIN \& ZUBIETA, p.211). En efecto, en sus apariciones públicas, abundan los ejemplos en que puede observarse este matrimonio entre el ejército y la familia. Podemos recordar el mensaje navideño del Presidente Videla el 26 de diciembre de 1977 en el que se dirigía a la familia argentina en forma personalizada, utilizando la forma "usted" para referirse a los padres, pero un caluroso "vos" al hablarle a los jóvenes, a quienes parecía comprender, cuya vida describe como "emotivamente inestable pero moralmente idealista." Videla finalizaba su mensaje diciendo:

\footnotetext{
A todos los convoco bajo el signo de la unión nacional, dentro de ámbito de la familia, frente a frente con el rostro de ese niño Dios, para que hagamos un examen de nuestras conciencias (BLAUSTEIN \& ZUBIETA, p.226).
}

El texto del mensaje encerraba los caballitos de batalla de la retórica militar: la familia, la unión, la inestabilidad de la juventud y la invocación a Dios.

En cuanto al Almirante Massera, su vida como joven militar fue rígida y se casó a edad temprana, ya que un oficial soltero podia despertar sospechas de inestabilidad o de homosexualidad. ${ }^{5}$ En su biografía no autorizada de Massera, URIARTE (1991) destaca que el divorcio era raro entre los militares, ya que desprestigiaba su legajo, calificando de "irregular" su situación familiar. Sin embargo, el adulterio era moneda corriente y aceptado de modo tácito tanto entre los militares como entre sus esposas, aunque mantenido dentro de ciertos códigos de discreción. Uriarte señala algunas características particulares de las mujeres-esposas de los oficiales:

La infantización de las mujeres predisponía a los maridos al adulterio y confinaba gradualmente a las mujeres al lugar de una curiosa servidumbre, donde el marido lo era todo pero ellas tenian los resortes de la tranquilidad y la estabilidad doméstica. (URIARTE, 1991, p.37) 
Dentro de esta gran familia del Estado, el rol de la mujer no dejaba de ser tradicional. Las mujeres eran convocadas a cumplir su rol de madre. En una Carta abierta a las madres argentinas se exhortaba a reflexionar:

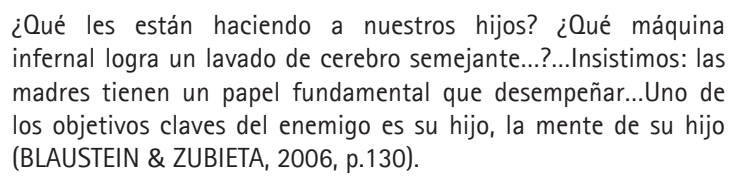

Es interesante destacar que Uriarte identifica una "secuela" en el lenguaje de las mujeres de los oficiales militares. Según su observación, estas mujeres solían llamar "señor" a cualquier militar delante de su rango, es decir, en lugar de decir, por ejemplo "el General Videla," decian "el señor General Videla." Por lo tanto, las reconstituciones y variaciones en el lenguaje eran observables en distintos ámbitos y niveles. Estas mujeres, que hacian las veces de secretarias o asistentes domésticas de los hombres en el poder, también se vieron afectadas, de una u otra forma, por la retórica oficial, aún en el microclima de sus hogares.

Al hacer un recorrido de las tapas de revistas y portadas de diarios de la época, se advierte que cuando los llamados subversivos que eran apresados o que morian en combate eran mujeres, se publicaban sus fotos en blanco y negro, y se acentuaba su condición de mujer. Ejemplos de esto son titulares como "Había estado detenida la joven que colocó la bomba" (LA PRENSA, 1976, p.1); "Trató de huir pero fue abatida antes de que pudiera hacer uso del veneno que llevaba encima" (LA RAZON, 1976, p.1); "Muerta" (REVISTA GENTE, 1976, p.1). De un recuadro titulado "La subversión sufrió un record de bajas" de Clarín del 3 de diciembre de 1976, llama la atención la frase que describe al responsable general de cierta organización "y su concubina, apodada Mimí, responsable del adoctrinamiento."6 Por lo que se deduce que esta mujer no sólo era mal vista por vivir en concubinato, pecado mortal para la Iglesia Católica, sino que llevaba un apodo, característica muchas veces típica de criminales, y además era el miembro más peligroso del grupo, ya que su función en el mismo era el "adoctrinamiento." Quien tiene a cargo el adoctrinamiento de los demás, suele suponerse que es quien posee conocimiento, teoría y doctrina. No es difícil deducir de estos ejemplos que entre líneas se señalaba que la mujer no debería recibir "demasiada" educación, ya que resultaría peligroso en sus manos. Para la ideología militar, la mujer debía dedicarse a cuidar a sus hijos, a protegerlos de los enemigos.

Además de cumplir funciones domésticas como el "ángel del hogar," pareciera que la mujer formara parte de un grupo aparte bajo la ideología propagada por el Proceso. Esto es evidente, por ejemplo, en una nota de Gente del 9 de junio de 1977, titulada "Subversión. Estas mujeres también han ganado la guerra," donde con gran dramatismo se describe el dolor de las madres que perdieron a sus hijos soldados en la guerra. Esto se contrapondría al discurso oficial que había calificado de "locas" a las Madres de Plaza de Mayo, que reclamaban por los cuerpos de sus hijos desaparecidos. ¿Acaso éstas madres sufrían menos que las otras? ¿Cómo se puede comparar el dolor de cada madre según la actividad de su hijo? La nota a la que se hace referencia aclara : "mujeres de militares de alto grado, de soldados, de bomberos, de policías, de ejecutivos, de empleados. A todas ellas les tocó la guerra. Perdieron algo irrecuperable. ... Ustedes también ganaron la guerra" (BLAUSTEIN \& ZUBIETA p.198, la bastardilla me pertenece). Si las mujeres no fuesen consideradas un subgrupo, o un grupo social aparte, el uso de la frase "ustedes también" no sería necesario en ese texto.

En efecto, el bombardeo de los medios de comunicación, especialmente de las revistas destinadas al público femenino, resaltaban la importancia del rol de la mujer en el Proceso. Al mismo tiempo, las Madres de Plaza de Mayo -actualmente conocidas y respetadas a nivel mundialeran censuradas, incomprendidas, tildadas de "locas" e indirectamente acusadas de no haber sabido educar correctamente a sus hijos. Las imágenes contrapuestas de las mujeres en roles similares eran ambivalentes. Dirigían un mensaje al público que las recibía, pre-estableciendo la recepción de las noticias de las muertes de hijos y limitando la libertad de opinión, o al menos, intentando manipularla. Mientras que ser madre de desaparecido era casi un delito, ser madre de soldado o de oficial militar era un honor. La distancia estética entre la lectura impuesta, "correcta," que pretendía eliminar cualquier otra lectura posible, y la libertad del lector se veía deliberadamente restringida. Puesto que este tipo de mensajes, desde las revistas y otros medios de comunicación, no podían ayudar sino destruir, estas clasificaciones de "tipos de madres" apuntaban a impartir una instrucción clara, ofreciendo continuas lecciones morales. Por lo tanto, no sólo restringía la libertad del público, sino que imponía en él una actitud moral.

El ser nacional real que permeaba las canciones de García, ya sea en su etapa pre-dictadura como en las etapas de La Máquina en las que se concentra nuestro análisis, estaba sustentado por ciertos pilares: (a) el rol de la mujer fuera de la concepción tradicional, (b) la denuncia al autoritarismo y la censura en forma poética y (c) la temporalidad de los gobiernos. El ser nacional real que proponía García estaba basado en la observación de lo cotidiano -en lugar de lo trascendental y mesiánico-; en el valor de la mujer como ser libre y no limitada al servicio de los demás; y en el lenguaje creativo, poético y metafórico, en oposición al discurso épico-político del régimen. Las canciones compuestas por García se coreaban en los recitales como símbolo de una unión cómplice entre los jóvenes que no se sentían representados por el ser nacional de la junta y que asistían a los conciertos para encontrarse y manifestarse en conjunto. El ejemplo más citado es el caso de "Canción de Alicia en el país", que se transformó en una especie de himno que se cantaba con fuerza colectiva en conciertos que llegaban a tener "hasta sesenta mil asistentes" (DENTE, 2000, p.69). No sólo la cantidad de personas presentes era inusual hasta ese entonces sino también la atmósfera de resistencia que 
se conformaba por un sólido frente común, compartido por artistas y su público. En una entrevista reciente, hablando sobre estos recitales y lo que acontecía durante los mismos, Charly García explicaba:

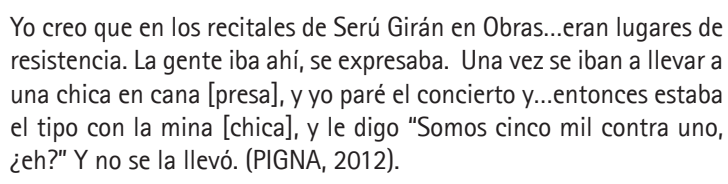

Yo creo que en los recitales de Serú Girán en Obras...eran lugares de resistencia. La gente iba ahí, se expresaba. Una vez se iban a llevar a una chica en cana [presa], y yo paré el concierto y...entonces estaba el tipo con la mina [chica], y le digo "Somos cinco mil contra uno, ¿eh?" Y no se la llevó. (PIGNA, 2012).

Además de anécdotas como ésta, la resistencia más importante ocurría precisamente en y a través de los textos de las canciones. De hecho, la banda que menciona Garcia en la cita anterior, Serú Girán, es posterior a La Máquina, cuyas canciones se analizan en este trabajo. Es decir que antes que los jóvenes utilizaran el espacio de los recitales como foco de resistencia colectiva, debió haber sido necesario que existiera una disidencia en forma de código cifrado que funcionara como elemento identificador común. Los jóvenes que interpretaban este tipo de mensaje codificado en la música que escuchaban, con el tiempo se darían cita en los conciertos. Esta etapa de mutua identificación y concertación habría ocurrido principalmente, sostenemos, durante la época de La Máquina.

En contraste al discurso oficial, en las letras de las canciones de La Máquina, García no utilizaba historias épicas ni conceptos mesiánicos. Por el contrario, su trabajo conformaba "un realismo sarcástico que no ofrecia ilusiones sino que pintaba un panorama desolado de la destrucción ideológica perpetrada por el gobierno militar" (PUJOL, 2005, p.66). Si bien la música de rock ha sido considerada idealista y cargada de sueños de una juventud opuesta al pragmatismo de los adultos, en este caso particular ocurría lo contrario, "nada era más realista que una canción de rock" (PUJOL, 2005, p.66). Las letras, que necesariamente debían ser cifradas y poco específicas, no relataban grandes fábulas sino que se concentraban en historias de lo cotidiano a la vez que se burlaban y exponían la "gran mentira" del ser nacional ideal.

\section{Hadas, princesas, actrices, bailarinas}

Uno de los elementos claves que cuestionaban estas canciones eran las ideas patriarcales en las que la familia es gobernada por la figura paterna y la mujer es, primero que nada, madre, obediente y sumisa. Una buena cantidad de composiciones de García desafían claramente esa propuesta. En los álbumes grabados en el periodo en cuestión se puede escuchar canciones en las cuales las protagonistas femeninas, lejos de estar en segundo plano, son heroínas y míticas, endiosadas y presentadas como seres mágicos:

Dama de colores,

lávame la cara y llévame

tan alto como para ver todo mi mal.

Diosa y heroina,

déjame la llave antes de ir

(GARCIA, "Bubulina", La máquina de hacer pájaros, 1976)
Ante la base ideológica sobre el rol de una mujer sumisa cuyo rol era principalmente el de madre "responsable", la música de García contraponía "otras mujeres" que no siempre eran "buenas" o sumisas. Sin embargo, cabe recordar que ésta no era una nueva idea de García. En su época pre-dictadura, con su banda Sui Generis ya había compuesto canciones como "Fabricante de mentiras" (que en su momento no pudo grabarse en estudio sino hasta años más tarde) pero que se cantaba en los recitales ante la ovación de los presentes. La canción relataba la historia de una colegiala que se había enamorado y había perdido su virginidad, sin embargo, en vez de sentirse avergonzada, como su educación tradicional hubiera dictaminado, la chica de la historia estaba feliz: "pero hay algo que nadie puede explicar: por qué la niña ríe en vez de llorar" (GARCIA, Sui Generis, 1975). Sui Generis habia mantenido a lo largo de toda su producción musical una visión alternativa de las mujeres, posicionándolas en situaciones fuera de las reglas establecidas. Así, Casandra no envejecía y era ilógica: era "hermosa como ayer, tan exacta como dos y dos son tres" ("El tuerto y los ciegos", Pequeñas anécdotas sobre las instituciones, 1974). Mariel era servida en lugar de servir: "el valiente capitán de la fragata cuando llega Mariel deja la gorra y sirve té con limón" ("Mariel y el Capitán", Vida, 1972). Muchas otras canciones presentaban a las mujeres como hadas ("Un hada, un cisne", Confesiones de invierno, 1973), soñadoras ("La niña juega en el gran jardín", Adiós Sui Generis I, 1975), "falsificadoras del querer" ("Pequeñas delicias de la vida conyugal", Pequeñas anécdotas sobre las instituciones, 1974); o libertinas que "se entregaban desnudas sobre la arena" ("Estación", Vida, 1972).

Siguiendo entonces con su estilo anterior, evidente en las canciones de Sui Generis, en el período de La Máquina, que coincide como ya hemos mencionado con el comienzo de la dictadura y los momentos más represivos del gobierno, estas características no se modifican, sino que, al igual que la represión, también se acentúan. Además, las cuestiones temáticas en los dos álbumes de Charly García con su banda La Máquina de Hacer Pájaros marcan un contraste filoso con las temáticas de los discursos de Videla y Massera. En efecto, estas canciones cuestionan y deconstruyen elementos centrales de la retórica del régimen. Por ejemplo, "Boletos, pases y abonos" (GARCÍA, La máquina de hacer pájaros, 1976) alude a "El rey burgués," de Rubén Darío, en la frase: "Soy el mendigo azul, el que cantó para el rey". El clásico de Rubén Dario distingue entre el gobernante poderoso y el poeta. Esta estrategia, en forma indudablemente tradicional, ubica a García en el contexto de la Argentina, como el poeta en contra del régimen opresor. Además, el poeta/músico en esta canción se dirige a las mujeres: "Madres, hijas, hermanas, van a escuchar" y les propone: "Soy el hijo de todas y el amante también, / ¿no se atreve, dulce mamá, a ser mi mujer infiel?". La descripción de la voz cantante como "el hijo y el amante de todas" persigue dos fines: por un lado, coloca a la mujer como un símbolo de la patria ("La Argentina"). Por otro, la descripción distorsiona el 
modelo tradicional de padre de familia bajo la concepción del ser nacional del Proceso. En lugar de ser el "jefe de hogar", es el amante secreto. Ante esta disyuntiva, la mujer/Argentina tendrá dos opciones: la que le ofrece el poeta que la amará clandestinamente o la que le ofrece el legítimo rey que "puede reír de tanto sufrir el frío y el calor y el dolor". El binomio es claro en la canción: belleza y poesía contra crueldad y sufrimiento. Elegir "ser infiel" implicaría liberarse del cruel rey.

Guiñándole un ojo a la audiencia, "Marilyn, la cenicienta y las mujeres" (GARCIÁ, Películas, 1977) combina tres protagonistas femeninas de la realidad y la ficción: Marilyn Monroe, la Cenicienta y Dorothy de El Mago de $O z$. Desde el comienzo de la canción se expresa claramente que la burbuja es insostenible: "Marilyn tomó demasiadas pastillas ayer, la habian dejado sola, le habian mentido". En lugar de su carrera artística y su glamour, se recuerda aquí la triste y solitaria muerte de Monroe, seducida por un mundo ilusorio hollywoodense. Del mismo modo, Cenicienta, quien salió en busca de su príncipe encantado: "nunca fue feliz, siempre fue una fregona vuelta princesa." Se destruye así la fantasía de los cuentos con finales felices. Estas mujeres, seducidas por el poder y el glamour, son atrapadas y sufren la desilusión, que puede ser fatal. La verdad, según esta canción, es que

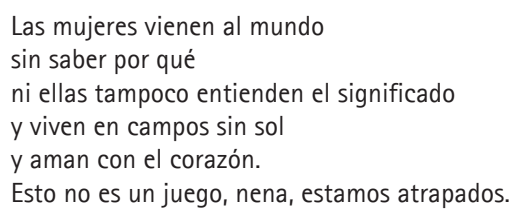

Si bien no se menciona a Dorothy por su nombre, sugestivamente, la canción comienza con algunos acordes de "Somewhere over the Rainbow", la melodía tal vez más popular asociada con el musical El Mago de $\mathrm{Oz}$. De la misma manera, la canción termina haciéndose eco de la frase icónica con que termina la historia de El Mago de Oz: "there's no place like home" (no hay mejor lugar que el propio hogar) a través del sonido de las voces de niños diciendo "todos tenemos hogar". La inclusión de estas referencias sutiles a $\mathrm{El}$ Mago de $\mathrm{Oz}$ es fascinante, ya que por lo general, los cuentos para niños tienen finales felices y se los piensa con mensajes positivos, sin embargo aquí la idea del final feliz es cuestionada. El cuento de hadas es utilizado como suplente de las fantasías que relataba el régimen en sus discursos, como se pudo ver en los ejemplos anteriores de la oratoria de Massera y Videla. Como $\mathrm{Oz}$, las promesas de unificación de los ciudadanos en un único e ideal ser nacional a través del cual los argentinos podrian vivir con honor y asumir sus papeles como hombres o mujeres, dentro de los parámetros de los valores tradicionalmente hispánicos, cristianos y occidentales, era antes los ojos de los jóvenes, una fantasía, un cuento de ficción infantil. En El mago de $\mathrm{Oz}$, Dorothy, al igual que la Argentina, es seducida por la ilusión de un mundo encantado donde ya no es una niña en edad escolar sino que va en busca de su destino. Como la tierra de $\mathrm{Oz}$, las promesas del Proceso comienzan con flores tecnicolores y el camino de baldosas amarillas hacia el futuro para luego convertirse en una pesadilla de escuadrones de la muerte, tortura y represión. Mientras vive en la tierra de fantasía, Dorothy -como las mujeres en la retórica del ser nacional, que deben ser madres y esposas serviciales y obedientes- no piensa en sí misma, sino que se preocupa por los demás. Su objetivo es ayudar al Hombre de Lata, al Espantapájaros y al León a cumplir sus sueños sin deparar en cuál es el deseo de su propio corazón. En cierto momento, al igual que los argentinos, Dorothy se da cuenta que la tierra de ensueño no es la perfección que parecía ser y extraña a sus familiares que han desaparecido de su vida. Comprende entonces que lo que más anhela en su vida existe en el viejo e imperfecto mundo que dejó atrás. Al final de la historia, encontrándose atrapada en una pesadilla, Dorothy se desespera por volver a su hogar. La Bruja Buena aparece para explicarle que siempre había tenido el poder de escapar de este lugar "ideal" y volver a su casa, sólo debía elegir. Como los argentinos, es ella quien debe acabar con la pesadilla. En efecto, Dorothy/la Argentina necesita aprender por sí misma que su esencia/ser nacional no depende de un país ideal/la retórica del régimen, sino de su vida con sus seres queridos/su realidad.

A nivel personal, la canción advierte a las mujeres sobre la invalidez de someterse al mito fabricado del final feliz de los cuentos y las anima a buscar y desarrollar su propio potencial y sus intereses personales. Sin embargo, también hay una generalización: "estamos atrapados" (todos), o "Todos tenemos hogar". Estas líneas sugieren un alcance más amplio que incluye a todos los argentinos, independientemente de su género: todo el pais ha sucumbido en la seducción de un príncipe verborrágico que resultó ser un charlatán. La solución viable es despertar del sueño de un único ser nacional ideal y volver a la realidad de un ser nacional real.

Mientras que el Proceso se autodefinía como la auténtica y única identidad de los argentinos, la dicotomía presentada en las canciones de García definía a la gente y al gobierno como opuestos. Mientras que la junta vaticinaba que triunfaría en la unificación de todos los argentinos y que recuperaría la identidad nacional, canciones como "Boletos, pases, abonos" y "Por probar el vino y el agua salada" (GARCÍA, La máquina de hacer pájaros, 1976) destruían el engaño. Esta última relata la parábola de una mujer muy vivaz y alegre: "Julia, la bailarina" quien se convierte en la prometida de un rey subyugador. En esta historia, Julia es asociada con diversas cosas de la vida cotidiana y con la vitalidad. "Baila con tachos y calles y el mar," prueba "el vino y el agua salada" -símbolos poéticos clásicamente asociados al placer y el dolor- en definitiva, es la personificación de la vida vivida a pleno. La figura de la mujer, en esta canción, es capaz de traicionar y en lugar de sentir culpa o remordimiento, lo disfruta. Es un mundo en el que "las niñas han regalado sus piernas al mal", muy lejos de los "ángeles del hogar" del ser nacional ideal. 
"Películas (Qué se puede hacer salvo ver)" (GARCÍA, Películas, 1977) es una clara alusión a la falta de libertad bajo el régimen militar: como casi todo estaba prohibido, lo único que se podía hacer era ver películas. Esta canción, que también sirve de título al segundo álbum de La Máquina, es lo opuesto a la retórica triunfal del discurso oficial en el que el hombre se presenta como el héroe que salva a la dama en peligro. Por el contrario, narra la historia de un hombre muy callado que idolatra a la mujer que ve en la pantalla del cine ("mi corazón es de ella"). Con sus "dos gatos que se duermen sobre la TV", sueña acercarse a ella: "me acercaré al convertible / le diré: quiero ser libre, llévame, por favor". Esta inversión de "quién rescata a quién" es acentuada a través de la inserción inesperada de un audio clip contrastante muy interesante. Se trata del sonido original de parte del diálogo de la película argentina Casa de muñecas, de 1943, que funciona como una suerte de epígrafe que guía a la audiencia para poner la canción en perspectiva. Este audio es tal vez la clave para la interpretación de la canción en este contexto:

\footnotetext{
Osvaldo: Tal vez mis palabras te hayan parecido egoistas; pero piensa que era mi honor el que estaba en peligro. Los hombres no sabemos dar la honra por amor...

Nora: Las mujeres sí; ese es nuestro orgullo...
} (ARANCIBIA, 1943)

El breve diálogo entre Delia Garcés (Nora) y Jorge Rigaud (Osvaldo) ejemplifica el ideal tradicional de comportamiento machista y forma de este modo un contraste con la actitud apacible del protagonista de la canción de García. Osvaldo, en Casa de muñecas, prioriza claramente el honor por sobre el amor, es un "hombre" tradicional para el que el honor es lo más importante. El personaje de Nora propone que la mujer es lo contrario, es capaz de priorizar el amor ante el honor, la libertad y tal vez hasta el respeto propio. La voz masculina en la canción de García está más cerca de una idealización estereotípica de la figura femenina que con los valores patriarcales y machistas presentados en Osvaldo de la pantalla. Al protagonista de la canción no le importa sacrificar su honor por su amada, incluso asegura que "me acercaré al convertible, le diré: quiero ser libre, llévame, por favor". Probablemente el objetivo perseguido era demostrar que valorar el amor por sobre el honor no era una característica "femenina" como la retórica del régimen afirmara, sino una cualidad humana.

De este modo, a los opuestos binarios alegría versus crueldad, vitalidad versus muerte, "Películas" agregaba amor versus honor. La retórica del discurso militar proyectaba un mundo donde lo más importante era el honor, el sacrificio y el deber, donde las mujeres servian al hombre y los hombres a la nación. En la visión del mundo de García, como es evidente en sus composiciones musicales de esa época, lo más importante era el amor, la vida y la alegría; es un mundo donde no importaban las jerarquías porque esas distancias eran destruidas por el amor.
El concepto de amor versus honor es quizás el que determina la diferencia más clara entre la dialéctica del ser nacional ideal del Proceso y el ser nacional real de la juventud que seguía a García y su música, porque define un concepto clave. En la misma época en que Charly García componía estas canciones donde las mujeres eran diosas, hadas y bailarinas, surgían las conocidas Madres de Plaza de Mayo, mencionadas previamente en este artículo, que comenzaron sus marchas en búsqueda de sus hijos desaparecidos. Estas mujeres que supieron convertir su debilidad (su condición de mujer bajo el régimen militar) en su mayor fortaleza, habían sido bautizadas por el régimen como "las locas de la Plaza de Mayo" (FEITLOWITZ, 1998, p.33). En efecto, a través de resaltar sus roles como madres y atreverse a desafiar al régimen, favoreciendo el amor antes que el honor, las Madres de Plaza de Mayo resistieron agresiones, insultos y hasta persecución y tortura, pero no cesaron sus protestas y reclamos en el espacio público de la plaza. Según el punto de vista del régimen y su ideal de ser nacional, aquél que arriesgaba su vida por amor era loco. Sin embargo, según la visión de Charly García y los miles de jóvenes que asistían a estos conciertos y cantaban sus canciones, la locura era elegir la muerte en defensa del "honor". Tal cual lo había expresado en una de sus canciones anteriores al período dictatorial, para García "la locura [era] poder ver más allá" ("El tuerto y los ciegos", Pequeñas anécdotas sobre las instituciones, 1974).

\section{Conclusión}

En este estudio, a través del análisis del discurso del Proceso de Reorganización Nacional en sus declaraciones y comunicados oficiales, se ha demostrado que el régimen intentaba la reinstauración de valores correspondientes a un pasado imaginado, de raíces hispánicas y patriarcales, que constituía casi una caricatura exagerada de ideales clásicos como el "ángel del hogar" y el "código de honor". Estos valores se imponían desde diversos medios para que la población los adoptara y se transformara acordemente. El discurso poético de Charly García con su banda La Máquina de Hacer Pájaros contradecía ese discurso sutilmente, en momentos en que era sumamente peligroso disentir. La retórica triunfal del régimen era deconstruida a través de un contradiscurso que lejos de emular esas características épicas, era poético y bello, aunque cotidiano y aparentemente imperfecto. La mujer era idealizada y la autoridad masculina era satirizada y cuestionada de diversas maneras, siendo el honor destronado para consagrar al amor, ideal de la cultura hippie a la que el régimen intentaba destruir. En síntesis, la grandiosidad del ser nacionaly de una unidad ideal era comparada a un cuento de hadas, donde la protagonista (la nación) caía en las garras de un príncipe que en lugar de ser encantado, era un charlatán mentiroso.

En definitiva, todas estas canciones conforman un sutil aunque potente contradiscurso. Notablemente, 
la última canción del álbum de 1977 de La Máquina era mucho más directa y consecuentemente, tal vez peligrosa. Hasta ese momento se ofrecían alternativas al autoritarismo del Proceso pero este tema, justo el último de esta etapa de García, se arriesgaba a subrayar más claramente que la visión del régimen era nada más que un discurso vacío de promesas:

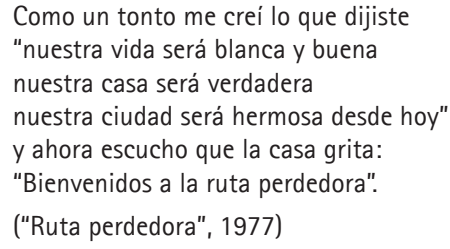

Conformando un contra-discurso a la retórica del Proceso, no quedan dudas que estos dos álbumes grabados por La Máquina, que habian sido considerados por la crítica menos políticos y más poéticos que los posteriores de García, fueron en verdad, sumamente políticos en la única forma en que se podía disentir: a través de una poesía sofisticada y cifrando el contradiscurso político cuidadosamente. En lugar del discurso basado en una familia tradicional, la guerra, el honor y el cumplimiento de los objetivos del plan "cueste lo que cueste", que se escuchaba en todos los ámbitos públicos, las composiciones poéticas de García recorrían esos mismos ámbitos hablando de la identidad argentina sin necesidad de diferencias genéricas impuestas, basada en los principios de la vida, el amor y la alegría.
El efecto de estas poéticas de resistencia entre los jóvenes que asistian a estos conciertos es algo que ya hemos analizado en otra oportunidad (FAVORETTO \& WILSON, 2010, p.50-51). Algunos años después, cuando las condiciones habian cambiado completamente, Garcia motivaba y energizaba a multitudes enormes que asistían a los conciertos de su siguiente banda Serú Girán. Como lo expresaba el músico en 1981,

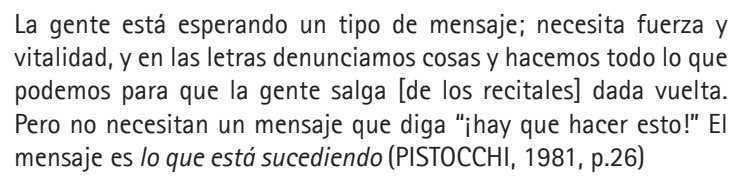

Sin embargo, en la época de La Máquina, una actitud contestaria más abierta o transgresora habría sido imposible sin arriesgar la vida. En ese contexto, el modo en que las letras de las canciones de García subvertían el discurso oficial no deja de resultar admirable. Sin tener en cuenta la recepción o efecto de su música, un artista se expresa siempre, tenga o no una audiencia. En tiempos de represión, esa necesidad de expresarse es mayor. Como diría García, años después: "Lo único que se podía hacer, salvo ir a ver películas, era, para músico o compositor, sacarse toda la bronca; y a la vez hacerlo de una forma que se podía editar el disco" (PIGNA, 2012). García no sólo logró expresarse a sí mismo sino que ayudó a muchos argentinos -y argentinas en especial- a aferrarse a la vida a pesar de que los rodeaba la muerte, convirtiéndose en la voz de toda una generación de argentinos censurados.

\section{Referencias bibliográficas}

ALABARCES, Pablo. Entre Gatos y Violadores. El rock nacional en la cultura argentina. Buenos Aires: Colihue, 1995.

ARANCIBIA, Ernesto. Casa de muñecas. Estudios San Miguel, 1943.

AVELLANEDA, Andrés. Censura, Autoritarismo y Cultura: Argentina 1960-1983. 2 vols. Junín, Buenos Aires: Centro Editor de América Latina, 1986.

. "El discurso de censura cultural en la Argentina, 1960-1983: Notas para su análisis." Pailler, Claire, Les Amériques et I'Europe: Voyage-Emigration-Exil. Toulouse: Univ. de Toulouse-Le Mirail, 1985, p.185-207.

BELTRAN FUENTES, Alfredo. La ideología autoritaria del rock nacional. Buenos Aires: Ceal, 1996.

BLAUSTEIN, Eduardo y Martín ZUBIETA. Decíamos ayer: La prensa argentina bajo el Proceso. Buenos Aires: Ediciones Colihue, 2006.

CLARIN. Suplemento especial, 24 marzo 2006.

CLARIN, Diario argentino. Buenos Aires, 3 de diciembre de 1976.

DENTE, Miguel Angel. Transgresores: Spinetta/García/ Páez. Buenos Aires: Distal, 2000.

FAVORETTO, Mara. Alegoría e ironía bajo censura en la Argentina del Proceso (1976-1983) New York: Edwin Mellen Press, 2010.

FAVORETTO, Mara y Timothy WILSON. "'Entertaining' the Notion of Change: The Transformative Power of Performance in Argentine Pop." Popular Entertainment Studies 1.2, 2010, no pag. 
FEITLOWITZ, Marguerite. A lexicon of Terror: Argentina and the Legacies of Torture. New York, Oxford U P, 1998.

FOSTER, Davis William. Violence in Argentinean Literature:Cultural Responses to Tyranny. Columbia and London: University of Missouri Press, 1995.

FRITH, Simon. "Music and Identity" Questions of Cultural Identity, Hall, S. y Paul du Gay eds. Los Angeles, London, New Delhi, Singapore, Washington DC: Sage, 1996.

GRINBERG, Miguel. Cómo Vino La Mano. Orígenes Del Rock Argentino. Buenos Aires: Gourmet Musical Ediciones, 2008. Print.

INVERNIZZI, Hernán. Los libros son tuyos: Políticos, académicos y militares: Ia dictadura en Eudeba. Buenos Aires: Eudeba, 2005.

INVERNIZZI, Hernán y Judith GOCIOL. Un golpe a los libros: Represión a la cultura durante la última dictadura militar. Buenos Aires: Eudeba, 2002.

KAMIN, Bebe. Adios Sui Generis (Film Documentary of the Sept. 5, 1975 Concert in Luna Park). MBC Producciones, 1975. KLEIN, Naomi. The Shock Doctrine: The Rise of Disaster Capitalism. New York: Metropolitan Books, 2007.

LA PRENSA, Diario argentino, Buenos Aires: 19 de junio de 1976.

LA RAZON, Diario argentino, Buenos Aires: 3 de diciembre de 1976.

MARCHI, Sergio. No digas nada. Una vida de Charly García. Ed. Actualizada. Buenos Aires: De Bolsillo, 2007.

MASSERA, Emilio. El Camino a la democracia. Caracas: El Cid Editor, 1979.

OLIVERI, Marcelo. Eramos tan hippies, Buenos Aires: Corregidor, 2007.

PISTOCCHI, Jorge. "Entrevista con Charly Garcia." Expreso Imaginario. Diciembre 1981, p.24-28.

PUJOL, Sergio. Rock y dictadura: Crónica de una generación (1976-1983). Buenos Aires: Emecé Editores, 2005.

REVISTA GENTE, Buenos Aires: Editorial Atlántida: 6 de diciembre de 1976.

.9 de junio de 1977

SANCHEZ, Jorge. Leyendas del rock. Charly García-1a ed. Clarín. Buenos Aires: Arte Gráfico Editorial Argentina S.A., 2007.

TAYLOR, Diana. Disappearing Acts: Spectacles of Gender and Nationalism in Argentina's "Dirty War." Durham: Duke University Press, 1997.

URIARTE, Claudio. Amirante Cero: Biografía no autorizada de Emilio Eduardo Massera. Buenos Aires: Planeta, 1991.

VILA, Pablo. "Rock nacional and Dictatorship in Argentina." Popular music. 6.2 (1987): 129-148.

WILSON, Timothy. "Starmakers: Dictators, Songwriters, and the Negotiation of Censorship in the Argentine Dirty War." A Contracorriente. 6.1 (2008), 50-75.

"Argentina's Proceso: Societal Reform through Premeditated Terror." The Development of Institutions of Human Rights: A Comparative Study. Eds. Lilian Barria and Steven Roper. New York: Palgrave Macmillan, 2010.

\section{Discografía}

GARCIA, Charly. La Máquina de Hacer Pájaros. La máquina de hacer pájaros. Microfon, Sony BMG, 1976.

. La Máquina de Hacer Pájaros. Películas. Microfon, Sony BMG, 1977.

. Serú Girán. Serú Girán. Music Hall, 1978.

. Serú Girán. La grasa de las capitales. Music Hall, 1979.

. Sui Generis. Vida. Microfón, Sony BMG, 1972.

. Sui Generis. Confesiones de invierno. Microfón, Sony BMG, 1973.

.Sui Generis. Pequeñas anécdotas sobre las instituciones. Microfón, Sony BMG, 1974.

.Sui Generis. Adiós Sui Generis I. Microfón, Sony BMG, 1975.

.Sui Generis. Adiós Sui Generis II. Microfón, Sony BMG, 1975.

\section{Sitios electrónicos}

Dirección General de Cultura y Educación de la Provincia de Buenos Aires. ABC.gov.ar. http://www.elhistoriador.com.ar/ documentos/dictadura/proclama_del_24_de_marzo_de_1976.php

Nuncamas.org. "Directive No. 604/79 of the Commander-in-Chief of the Army" (Continuation of the Offensive against Subversion), May 1979." Doc. 54. April 2009. http://www.nuncamas.org/document/militar/60479.htm

PIGNA, Felipe. Interview with Charly Garcia. "Que fue de tu vida: Felipe Pigna y Charly Garcia" Buenos Aires, Canal 7, Jan.

19, 2012. http://www.youtube.com/watch?v=uzz8CsMqNp8 


\section{Notas}

1 El rock nacional argentino, en especial el compuesto durante la dictadura, ha recibido un importante caudal de atención en el ámbito académico. Ver los trabajos de VILA (1987), PUJOL (2005), SANCHEZ (2007), OLIVERI (2007), BELTRAN FUENTES (1996), GRINBERG (2008), FAVORETTO (2010) y WILSON (2008). Ya es sabido que, curiosamente, el rock nacional floreció y se desarrolló con más fuerza gracias a la represión y censura del régimen militar. Los represores militares obtuvieron un efecto inesperado en su plan: en lugar de contenerlo, impulsaron el desarrollo del rock nacional.

2 Su banda Serú Girán fue la primera megabanda de ese género con giras constantes y actuaciones multitudinarias como por ejemplo el show gratuito organizado en el predio de La Rural en 1980, que reunió la cifra para entonces inédita de 60.000 personas (SANCHEZ, 2007, p.33).

3 Para un estudio detallado del funcionamiento del aparato censor en esta época ver FAVORETTO (2010, p.11-36).

4 Durante la dictadura, con las universidades controladas por las autoridades militares, el muy limitado grupo estudiantil y la prohibición de partidos políticos, los jóvenes se refugiaron en el rock argentino. El periodo 1976-77 fue marcado por la inmensa cantidad de conciertos de rock nacional, muchos de ellos en el Luna Park, el estadio cubierto más grande de Buenos Aires con capacidad para 15.000 personas. Estos conciertos que, como explica VILA (1987, p.135), servían más a un propósito social que musical, son un ejemplo de un acto político encubierto. Los conciertos eran como rituales de la resistencia, en los que la música era el medio de comunicación, y donde muchas veces, las canciones que habían sido censuradas, se tocaban en público.

5 Un ejemplo de la retórica paternalista de Massera se puede ver en su Mensaje a la Ciudadanía, en agosto de 1978, cuando al retirarse oficialmente como almirante, dice:

El poder es un pacto con la soledad, aunque yo traté de romperlo permanentemente cada vez que pude. Muchas veces, al volver a mi casa a horas avanzadas de la noche, veía luces encendidas en las ventanas de ustedes y me preguntaba quién viviría allí, de qué manera los afectaban las decisiones que habiamos tomado ese dia, en qué medida estaba cumpliendo yo con mi obligación de velar por el destino de mis compatriotas, y hubiera querido entrar en cada casa y hablarles, y escucharlos, y preguntarles por sus alegrias y sus decepciones... (URIARTE, 1991, p.212)

6 Todos estos artículos están publicados en BLAUSTEIN \& ZUBIETA (2006, p.131, 161, 165 y 166).

Mara Favoretto is a Lecturer in Spanish and Latin American Studies at the University of Melbourne, Australia, where she coordinates and teaches a range of Language and Culture Studies subjects. She specializes in contemporary popular culture and popular music lyrics as counter discourse in cultural crisis. Her research interests include rhetorical tropes used to encode subversive messages under the constraints of censorship and cultural expressions of resistance in Latin American society. She is the author of Alegoría e ironía bajo censura en la Argentina del Proceso (New York: Edwin Mellen Press, 2010)

Timothy Wilson is an Associate Professor of Spanish and Literature at the University of Alaska Fairbanks whose work centers on music, identity, and popular cultures of resistance in Latin America. Dr. Wilson is the author of numerous articles on Argentine rock music and dictatorship, and several others on musician Kevin Johansen and hybrid identities in the globalized world. 